\title{
MAPEANDO A REDE RURAL DE DESENVOLVIMENTO DA PECUÁRIA FAMILIAR NA REGIÃO CENTRO-SUL DO RIO GRANDE DO SUL
}

\author{
MAPPING RURAL WEB DEVELOPMENT OF THE FAMILY \\ LIVESTOCK IN CENTRE SOUTH REGION OF RIO GRANDE \\ DO SUL
}

\author{
Marcelo Porto Nicola \\ Universidade Federal do Rio Grande do Sul - Porto Alegre - RS - Brasil \\ Flávia Charão-Marques \\ Universidade Federal do Rio Grande do Sul - Porto Alegre - RS - Brasil
}

\begin{abstract}
Resumo: A rede rural é um conjunto de recursos, atores, ações, transações e arranjos que estão entrelaçados, determinando a natureza da atividade rural em um lugar específico. O trabalho objetiva mapear a rede rural da pecuária familiar na região Centro-Sul rio-grandense através do exame da realidade local da experiência que acontece em São Jerônimo, Butiá e com desdobramentos regionais. O referencial teórico se apoia na noção de desenvolvimento rural como uma rede multidimensional em constante desdobramento. A metodologia empregou levantamentos documentais; observação participante e entrevistas semiestruturadas com informantes-chave. Ficou evidenciado que a rede rural foi tomando forma à medida que se resgatou aspectos relativos ao seu surgimento e sua evolução, até chegar ao esboço das atribuições atuais, cuja composição abrange atores sociais, transações, arranjos e recursos físicos, culturais, históricos, técnicos, ambientais, sociais e econômicos. Nesse processo, destacou-se uma de suas características definidoras, que é o entrelaçamento entre os distintos elementos, dispostos e direcionados, prioritariamente, em benefício de um segmento específico e vulnerável, os pecuaristas familiares.
\end{abstract}

Palavras-chave: Rede rural. Pecuária familiar. Espaço protegido. Desenvolvimento rural.

Abstract: Rural web is an ensemble of resources, actors, actions, transactions and arrangements that are interlaced, defining the nature of rural activity in a specific place. This paper aims to map the family livestock rural web in Centre South region of Rio Grande do Sul through examining local reality of experience that is happening in 
São Jerônimo, Butiá and its regional unfolding. The methodology employed documentary surveys, participant observation; and semi-structured interviews to key informants. It was evident that the rural web was taking shape as it was rescuing aspects related to its appearance and evolution until its current characteristics, whose composition covers social actors, transactions, arrangements and physical, cultural, historical, technical, environmental, social and economic resources. In this process, it was highlighted one of rural web essential features, which is the intertwining among distinct elements, placed and targeted, prioritizing, to benefit a specific and vulnerable social segment, the family livestock.

Keywords: Web rural. Family livestock. Niche. Rural Development. 


\section{Introdução}

Rede rural é uma noção central para a análise proposta neste artigo, correspondendo a interações, inter-relações, encontros e reciprocidades que existem entre atores, recursos, atividades (sociais, econômicas, políticas ou culturais), setores e lugares dentro de áreas rurais (PLOEG et al, 2008). Um entrelaçamento relativamente coerente entre estes componentes, por sua vez, apoia e fortalece o processo de desenvolvimento rural (MARSDEN; PLOEG, 2008; PLOEG, 2011). Os autores salientam, a fim de diferenciá-la dos outros tipos de redes presentes nos espaços rurais, que as características da rede rural, e somente elas, estão intimamente ligadas à natureza transicional e contracorrente dos processos de desenvolvimento (MARSDEN; PLOEG, 2008).

De acordo com Ray (1999), o desenvolvimento deveria ser conceituado como um processo de animação das capacidades nativas, as quais, uma vez ativadas, conduziriam uma dinâmica autossustentada de desenvolvimento. No entanto, reconhecendo que este não é um processo linear, aciona-se, aqui, o argumento de Ploeg (2000), que ressalta o desenvolvimento rural como um processo multinível e multifacetado que emerge como uma série de respostas ao paradigma da modernização. Assim, as dinâmicas de revitalização do rural, que, potencialmente, podem torná-lo mais atrativo, acessível, valioso e útil para a sociedade como um todo, passam pela criação de novos produtos e serviços, criação de novos mercados e formas de redução de custos, implicando na valorização da agricultura familiar/camponesa e na redefinição da relação campo-cidade, associada, eventualmente, com a transferência de recursos da economia urbana para a rural.

Por outro lado, tais processos são pautados (ou ameaçados) por condicionantes estruturais mais amplos, cujas rupturas podem se apresentar como muito difíceis, de maneira que eles se mostram como transicionais, sobretudo por se constituírem como dinâmicas contrárias aos regimes sociotécnicos ${ }^{1}$ prevalentes. Justamente porque a

\footnotetext{
'Regime sociotécnico é uma noção proposta desde uma Perspectiva Multinível para análise da mudança social e técnica, corresponde a um conjunto de regras semicoerentes que estruturam sistemas sociotécnicos ou, ainda, noção que serve para
} 
emergência das redes rurais, muitas vezes, coloca-se em sentido oposto à trajetória auto evidente da modernização (ROEP; WISKERKE, 2004) é que surge a necessidade de enfrentar autonomamente o interesse seletivo do capital e do mercado e os preconceitos do conhecimento científico hegemônico. Para Ploeg et al (2004) e Ploeg e Marsden (2008), esse enfrentamento pode ser facilitado pela criação de um "espaço protegido", configurado por um conjunto de atores sociais (entidades, organizações, empresas, poder público, agricultores e outros), atividades, recursos, instituições, níveis e redes que deliberadamente irão se articular de modo a criar oportunidades e aumentar as chances para que respostas diferenciadas e criatividades prosperem.

Partindo, então, da ideia de que os desdobramentos de redes rurais podem ser considerados como processos de desenvolvimento rural, na medida em que se estabelecem relações de mutualidade, fortalecimento e causalidade entre os dois, este artigo propõe examinar um conjunto de recursos, atores, ações, transações e arranjos em comunidades de pecuaristas familiares na região Centro-Sul do Rio Grande do Sul - RS. Especificamente, objetiva-se dar visibilidade para a emergência de experiências localizadas, mobilizadas por diferentes atores sociais em resposta à dinâmica modernizadora e produtivista de desenvolvimento estabelecida na região. Nesse contexto, o estudo realizado considera dois eixos de uma mesma problemática, quais sejam, a vulnerabilidade da pecuária familiar e a ameaça ao Bioma Pampa.

A pesquisa, que foi realizada durante 2014 e 2015 , utilizou-se de procedimentos metodológicos que envolveram revisão de bibliografia, análise de documentos, coleta de dados secundários, entrevistas semiestruturadas com informantes-chave e observação participante em unidades produtivas da pecuária familiar, mas também em momentos de atividades coletivas, como reuniões, seminários, dias de campo, remates e outros. Dada a importância do contexto empírico para mapear a rede rural, foi fundamental identificar aspectos ambientais, materiais, tecnológicos, culturais e econômicos, tais como o solo, a topografia, a demografia, a história de ocupação do território, características dos

representar a gramática que interliga distintos regimes (e.g., científico, econômico, cultural, político), permitindo uma meta-coordenação entre eles (Geels, 2004). 
rebanhos, a cobertura vegetal, os artefatos tecnológicos (e.g. centros de manejo, balanças, máquinas), os conhecimentos, e os montantes financeiros aportados e em circulação. Igualmente foram identificados e incluídos na pesquisa políticas públicas, programas, atores sociais, suas associações, assim como, as instituições e as empresas (privadas e públicas) das quais fazem parte.

O texto traz, inicialmente, os aspectos levantados durante a aproximação com o empírico, passando, em seguida, a uma breve caracterização do espaço físico. Com isto, a próxima seção traz os elementos para entender os primórdios e a evolução da Rede Rural. A seção subseqüente apresenta os arranjos entre entidades, financiamentos regionais, ações e programas de modo a delinear a rede rural da pecuária familiar na região Centro-Sul do RS. Por último, são tecidas algumas considerações finais no intuito de contribuir sobre o debate do lugar e importância da pecuária familiar nos processos locais de desenvolvimento.

\section{Primeiras aproximações à região Centro-Sul}

Dezessete municípios ${ }^{2}$ compõem a chamada região Centro-Sul ${ }^{3}$, totalizando uma área superior a um milhão de hectares, com uma população de 250.000 habitantes. Tomado o Índice de Desenvolvimento Econômico e Social - IDESE, calculado para a totalidade da região, identifica-se um fraco dinamismo socioeconômico, com carências relativas importantes em infraestrutura e logística, renda, saúde e educação (RIO GRANDE DO SUL, 2010; FEE, 2013). Relativo à produção pecuária regional, destacam-se a criação de bovinos, presente em 10.504 propriedades, com um contingente de 270.000 animais, e a ovinocultura, presente em 1.450 estabelecimentos rurais, totalizando

\footnotetext{
2Arambaré, Arroio dos Ratos, Barão do Triunfo, Barra do Ribeiro, Butiá, Camaquã, Cerro Grande do Sul, Charqueadas, Chuvisca, Cristal, Dom Feliciano, Mariana Pimentel, Minas do Leão, São Jerônimo, Sentinela do Sul, Sertão Santana e Tapes.

30 território da região Centro Sul é dividido em duas sub-regiões. A carbonífera abrange os municípios localizados no vale do rio Jacuí, onde se encontra jazidas de carvão, sendo a exploração deste minério uma importante atividade econômica. A chamada costa doce é composta por municípios banhados pelo Lago Guaíba e Laguna dos Patos, destacando-se como característica específica o turismo (RIO GRANDE DO SUL, 2010).
} 
um rebanho aproximado de 63.000 animais (IBGE, 2006). Há também o registro do artesanato vinculado à pecuária. Estima-se que seja praticado por aproximadamente 50 artesãs ${ }^{4}$. Nessa atividade, são utilizadas matérias-primas diversas, derivadas especialmente da ovinocultura e da criação de bovinos

Baseado em dados da Pesquisa Agrícola Municipal (IBGE, 2013), estima-se que a área plantada de lavouras temporárias ultrapasse 16.000 hectares, com maior destaque para o cultivo de soja, arroz, milho e melancia. Observa-se, a partir de dados primários e secundários, que a área ocupada com a soja, desde o ano de 2009, é aquela que experimenta uma curva crescentemente vigorosa, dominando cada vez mais porções significativas da paisagem rural. Com relação às florestas plantadas, prevalece o eucalipto, mas também há áreas de acácia negra e pinheiro americano (pinus). Estima-se, com base em Relatório de Auditoria da Empresa CMPC Celulose Riograndense (BUREAU VERITAS CERTIFICATION, 2010 e IBGE, 2006), que a região apresente aproximadamente 45.000 hectares de sua superfície coberta com esses monocultivos florestais, algo em torno de $30 \%$ da superfície total.

Refletindo criticamente sobre este território ocupado com florestas plantadas, é fundamental destacar que a região Centro-Sul localiza-se na área fisiográfica do Pampa, e as suas áreas campestres estão sujeitas às mesmas ameaças sobre a biodiversidade e a sobrevivência deste bioma em outras regiões do estado, bem como do Uruguai e da Argentina. Nesse sentido Nabinger et al. (2005) enfatizam que esses ecossistemas têm sofrido, nas últimas seis décadas, uma escalada de agressões que ameaçam a sua existência, representadas, principalmente, pelo avanço do plantio de florestas exóticas e do cultivo de grãos, além do manejo inadequado dos campos, através de sobreexploração e uso excessivo de herbicidas. Sem esquecer que o recurso forrageiro nativo, disponível como cobertura vegetal dominante no bioma Pampa e nas áreas campestres do bioma Mata Atlântica do RS, tem se constituído num dos principais fundamentos da pecuária de corte explorada por agricultores familiares. Sendo que, na área da

${ }^{4} \mathrm{~A}$ estimativa foi feita com base em documentos dos Escritórios Municipais da Emater de São Jerônimo, Butiá e Arroio dos Ratos, e Rio Grande do Sul (2004). 
pesquisa (Figura 1), estima-se $\mathrm{s}^{5}$ um contingente aproximado de 600 famílias de pecuaristas familiares, mas, na região, o contingente pode ser superior a 1.200 famílias. Na área de concentração das ações da pesquisa, a população supera 50.000 habitantes, estimando-se que aproximadamente $90 \%$ estão domiciliados na zona urbana e $10 \%$, na zona rural, com variações importantes entre os municípios. São Jerônimo, por exemplo, tem $20 \%$ da população na zona rural, enquanto Butiá tem 5\% (IBGE, 2010).

${ }^{5}$ Estimativa com base no Censo Agropecuário 2006 (IBGE, 2006) e em levantamentos da pesquisa. 
Figura 1. Butiá, São Jerônimo e arredores em relação à região Centro Sul-RS

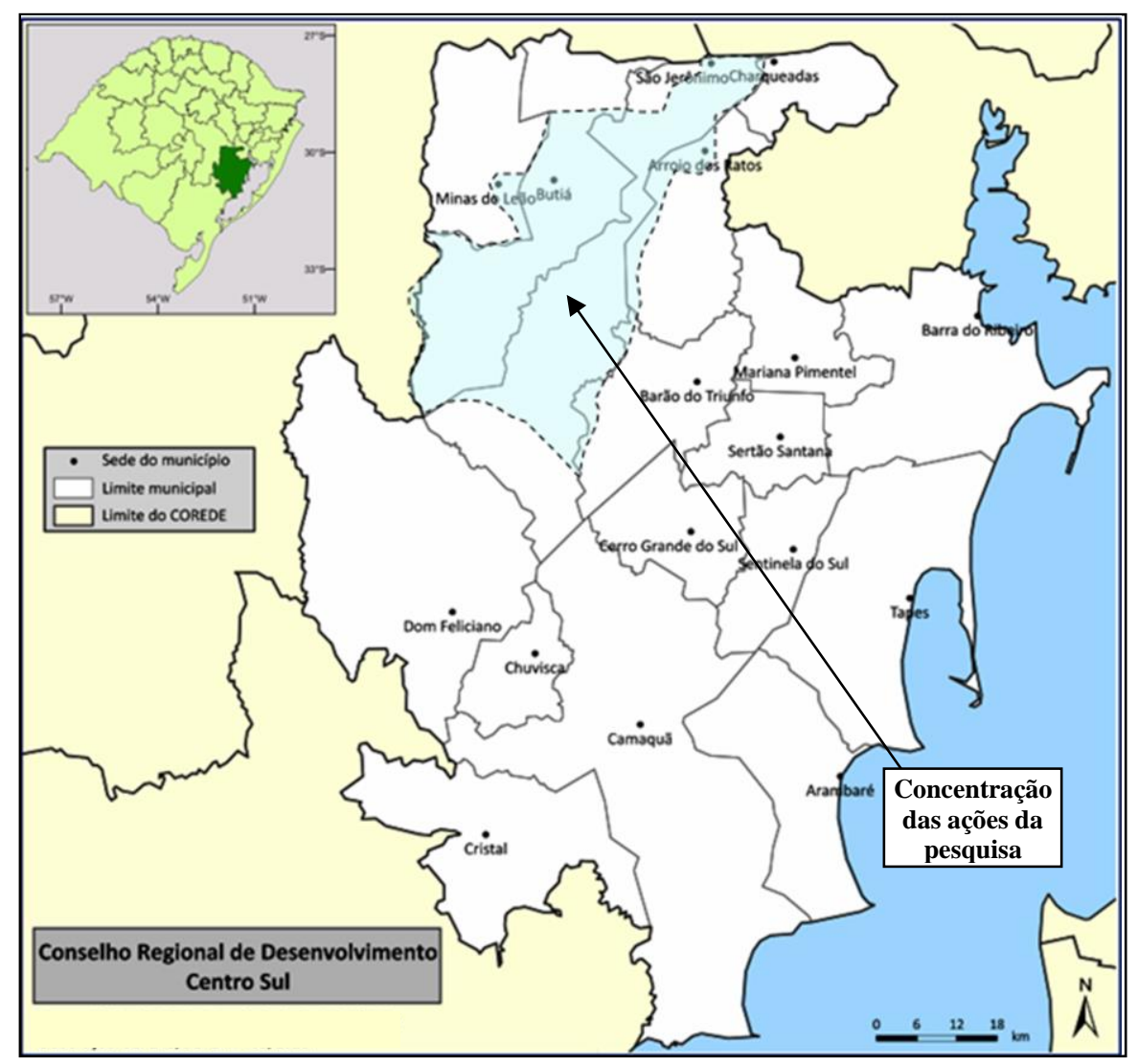

Fonte: elaborado sobre mapa do COREDE Centro Sul (RIO GRANDE DO SUL, 2015a).

A concentração da investigação nos dois municípios contíguos (Butiá e São Jerônimo) se justifica pelo fato de que, apesar do avanço dos monocultivos de grãos e florestas exóticas, as lideranças locais e regionais informavam, desde os primeiros contatos, que nesta zona a pecuária familiar é a mais proeminente de toda a região Centro-Sul. O detalhamento mais convincente da área de concentração das ações da pesquisa também teve influência dos trabalhos de Simch $(1943,1961)$, por permitir uma precisa especificação do ambiente local, a qual foi 
complementada pelo estudo dos Planos Municipais Ambientais de São Jerônimo e Butiá.

No município de São Jerônimo, o Instituto Brasileiro de Geografia e Estatística - IBGE (2006) aponta que existem em torno de 400 propriedades rurais de pecuária familiar, de um total geral superior a 1.300 estabelecimentos. Entretanto, o montante de agricultores familiares que criam algum efetivo de rebanho bovino é superior a 880 estabelecimentos (IBGE, 2006). Os pecuaristas familiares, propriamente ditos, estão localizados majoritariamente em sete comunidades rurais, em um total de 13 localidades (EMATER, 2013). A pecuária familiar destaca-se, então, nas comunidades Quitéria, Rincão dos Corrêas, Morrinhos, Palmeira, e Morrinhos Alto, mas também tem presença em Campo Bom e em Santo Antônio, de acordo com depoimento de um agente de desenvolvimento local.

Em Butiá, de acordo com IBGE (2009), o universo da agricultura familiar, perfaz um total de 226 estabelecimentos. Segundo os documentos de planejamento do Escritório Municipal da Emater, estima-se que existam, no município, 150 famílias de pecuaristas familiares de um universo ao redor de 320 famílias rurais, o que compreende aproximadamente $47 \%$ do total (EMATER, 2012a, 2012b, 2012c). As comunidades de pecuaristas e agricultores familiares estão espalhadas por todo o Município de Butiá, destacando-se as localidades Francisquinho, Cerro do Roque, Água Boa, Cerro do Clemente, Passo dos Carros e Passo da Estiva, todas representadas por associações de moradores (BUTIÁ, 2009).

Um dado que precisou ser estimado, tendo em conta a base municipal dos levantamentos do IBGE, é o efetivo total dos rebanhos da pecuária no talhão composto pelos municípios São Jerônimo, Butiá e arredores, manejados por pecuaristas familiares e não familiares. Com base nas Pesquisas da Pecuária Municipal de São Jerônimo e Butiá (IBGE, 2013) o número total de bovinos ultrapassa a cifra de 65.000 cabeças, enquanto que o número de ovinos se aproxima de 25.000 animais. $O$ artesanato, por sua vez, é representado por aproximadamente 21 artífices que se dedicam aos processos de lavagem, cardação, fiação e tecelagem da lã, e beneficiamento manual de outros produtos da pecuária, como couro, chifres, etc. 
As incursões da pesquisa permitiram constatar que muitas práticas e trajetórias em pecuária familiar no espaço representado na Figura 1, desdobram-se e, assim, conectam-se em rede com as ações que ocorrem em outros municípios da região, transpassando os limites permeáveis dessa fronteira, adquirindo, algumas delas, um caráter regional. O que será descrito a seguir.

A interação entre as localidades pode ser explicada, em parte, pelas raízes históricas da ocupação do espaço. O Município de São Jerônimo, conhecido em tempos longínquos como Passo das Tropas, teve sua origem a partir da Freguesia do Senhor Bom Jesus do Triumpho, com o início do seu povoamento no final do século XVIII, quando se denominava Novo Triumpho. O Passo das Tropas era o local mais seguro, na margem esquerda, para travessia dos rebanhos, pessoas e cargas no rio Jacuí, o qual se confrontava na margem direita com a Vila de Senhor Bom Jesus do Triunpho, onde o rio Taquari desemboca (SILVA, 2007).

Conforme Simch (1943), São Jerônimo foi elevado à condição de município em 1861, emancipando-se do Município São Bom Jesus do Triunpho, hoje denominado somente Triunfo. A superfície territorial do novo município perfazia em torno de $5.000 \mathrm{~km}^{2}$ e a maioria de seus limites administrativos foram estabelecidos por elementos naturais, tais como, rios e arroios.

Em 1872, na Província de São Pedro do Rio Grande, ainda na época do Brasil Império, o território rio-grandense era dividido por somente 28 municípios, dentre eles São Jerônimo, que abarcava uma ampla superfície territorial, com distritos, localidades e vilas, tais como, Vila Arroio dos Ratos, Curral Alto, Serra do Herval, Charqueadas e Vila Butiá (SILVA, 2007). Nos primórdios dessa vasta comuna, as áreas de terra dos atuais municípios de Charqueadas, Arroio dos Ratos, Butiá e Barão do Triunfo compunham a totalidade territorial de São Jerônimo, tornando-se, posteriormente, distritos administrativos oficiais (SIMCH, 1943, 1961).

Em 1940, como informa Simch (1943), Charqueadas, juntamente com a sede, fazia parte do primeiro distrito, a Vila Arroio dos Ratos do segundo, a Vila Butiá do terceiro e a Vila Barão do Triunfo do quarto distrito, os quais tinham subprefeitos nomeados para os efeitos 
administrativos. Cabos telefônicos subterrâneos, linhas de ônibus, linhas férreas e o fluxo diário de mercadorias e pessoas ligavam intensamente os distritos à sede municipal (SIMCH, 1943).

Num processo natural de evolução administrativa, em 1960, a divisão distrital de São Jerônimo se modifica, sendo acrescida por mais quatro distritos, totalizando oito. Através do desmembramento do antigo primeiro distrito, a Sede Municipal se torna o primeiro e Charqueadas o segundo. Arroio dos Ratos se torna o terceiro; Butiá, o quarto; e Barão do Triunfo passa a ser denominado o sétimo distrito. Surgem, nessa época, o quinto distrito de Leão, o sexto distrito de Morrinhos, e o oitavo distrito denominado Quitéria, antiga $2^{\mathrm{a}}$ zona do (quarto) distrito de Barão do Triunfo (SIMCH, 1961). As emancipações de algumas das Vilas distritais ocorreram em seguida, como por exemplo, Vila de Arroio dos Ratos, de Butiá e Barão do Triunfo, a partir de 1963, tornando-se assim novos municípios rio-grandenses.

Ao sobrepor os limites territoriais originais da época da emancipação de São Jerônimo, em 1861, num mapa com divisões administrativas atuais, a área de abrangência dessa comuna original abarcaria seis municípios da região Centro Sul, incluindo quatro antigos distritos, Charqueadas, Arroio dos Ratos, Butiá, Barão do Triunfo; e Minas de Leão, que se emancipou posteriormente de Butiá; além do próprio município mãe, São Jerônimo. Assim, parece evidente que muito da interação, fluxos, e transações verificadas entre as comunidades, pecuaristas e instituições que compõem o que metodologicamente está sendo chamado de espaço protegido da pecuária familiar é um desdobramento da relação original entre localidades que faziam parte de um mesmo município. Esta origem comum, apesar de estar longe de ser a explicação exclusiva, tem influído na promoção e manutenção de dinâmicas sociotécnicas na pecuária familiar que este trabalho se propõe a averiguar, evidenciando, em especial, as interações e conexões de uma rede rural.

\section{Características do Espaço Físico}

Recursos da natureza também compõem a rede rural, e são elementos fundamentais da coprodução e coevolução da pecuária. 
Assim, tornou-se importante, ainda que brevemente, trazer alguns aspectos ambientais relacionados à área em estudo. A superfície territorial original do Município de São Jerônimo é constituída por duas partes bem distintas, a planície e a serra. A planície, menor porção da área, é delimitada entre o volumoso rio Jacuí, ao norte, o arroio Francisquinho, a oeste, e o Município de Arroio dos Ratos, a leste. Esta fração se localiza ao norte da BR 290. A outra fração, caracterizada como serra, proporcionalmente maior, é formada pelo restante da superfície, em quase sua totalidade ao sul BR 290 até a Serra do Herval (SÃO JERÔNIMO, 2009; BUTIÁ, 2009; SIMCH, 1943).

Com os Planos Ambientais Municipais foi possível caracterizar zonas específicas quanto ao uso e aspectos ambientais, pormenorizando alguns detalhes dessas duas regiões mais amplas, a planície e a serra. A parte plana é ocupada significativamente por campos naturais e pastagens cultivadas voltadas para pecuária extensiva. Identifica-se também forte presença de extensas áreas de produção agrícola para cultivo do arroz com uso de tecnologia convencional baseada em agroquímicos e intenso manejo do solo, além de grande contingenciamento do espaço para uso militar no Município de Butiá. Nessa topografia com planícies e relevo suavemente ondulado, observa-se predomínio de vegetação formada por campos integrados com bosques de mata nativa e amplas superfícies de reflorestamento com espécies exóticas - eucalipto, principalmente, mas também acácia negra e pinus. A mata ciliar do rio Jacuí encontra-se razoavelmente bem preservada, mas nos arroios secundários as matas ciliares estão bastante afetadas negativamente pelos poluentes da atividade antrópica urbana, práticas de agricultura intensiva na cultura do arroz irrigado, e pressão exercida, em alguns pontos, pelas florestas exóticas de eucalipto (SÃO JERÔNIMO, 2009; BUTIÁ, 2009).

A serra, por sua vez, é explorada principalmente pela produção agropecuária. Observa-se, nessa fração, um gradiente de topografia em direção ao sul, desde levemente até fortemente ondulado, com alguns indicativos de erosão e mau uso do solo, atingindo altitude máxima de 445 metros na Serra do Azambuja, divisa com os municípios de Dom Feliciano e Pantano Grande. 
$\mathrm{Na}$ paisagem levemente ondulada, evidenciam-se médias e grandes propriedades, com predominância de campos e pastagens voltadas para a pecuária extensiva, amplas florestas de eucalipto, e cultivo anual com melancia e arroz irrigado, em solos enquadrados nas classes III, IV e V6. É, ainda, uma zona considerada de transição entre a planície e serra e está mais evidenciada no Município de São Jerônimo, com pequena extensão territorial, mas também aparece em Butiá (SÃO JERÔNIMO, 2009; BUTIÁ, 2009).

$\mathrm{Na}$ medida em que a superfície se enruga em direção à Serra do Herval, predomina a presença de comunidades rurais ocupadas com atividades agropecuárias familiares em pequenas e médias propriedades, com limitações significativas para o desenvolvimento da produtividade agrícola, em solos enquadrados nas classes III, IV, V, VI VII e VIII. Nessa zona, é onde se concentra a maioria da população rural, com significativa atuação comunitária e densidade demográfica. A região da serra apresenta áreas significativas de cultivo do fumo, campos e pastagens voltadas à pecuária extensiva com criação de bovinos, ovinos e equinos, lavouras de subsistência, e as florestas de eucalipto e acácia são marcantes na paisagem (SÃO JERÔNIMO, 2009; BUTIÁ, 2009).

Até aqui, foram apreendidos alguns elementos da rede rural relacionados a aspectos socioeconômicos, históricos e aos recursos naturais presentes na realidade local e regional. Em seguida, busca-se elucidar práticas e trajetórias levadas adiante por múltiplos atores que vão auxiliar, juntamente com os elementos já mencionados, dar contornos à abrangência e às feições da rede rural.

\section{A Evolução da Rede Rural: as Interações, os Projetos e os Programas}

\footnotetext{
6De acordo com o Levantamento da Capacidade de Uso da Terra (RIO GRANDE DO SUL, 1985), as classes de solo I, II e III são aquelas que se prestam ao cultivo continuado de culturas anuais; a classe IV apresenta restrições importantes ao uso continuado do solo com cultivos anuais; as classes $\mathrm{V}$ e VI são impeditivas aos cultivos anuais, mas se prestam aos permanentes como silvicultura e pastagens; a classe VII além de inviável aos cultivos anuais, apresenta severas restrições aos cultivos permanentes como silvicultura e pastagens; a classe VIII abarca as terras não utilizáveis para agricultura, pecuária ou silvicultura, sendo recomendadas para preservação da fauna e flora, recreação e turismo.
} 
Existem registros de propostas de mudanças técnicas no manejo dos rebanhos desde o século XVIII. Nesse período de mais de dois séculos, há indícios de estímulos governamentais e mercadológicos que, parcialmente, contribuíram para as transformações vividas na região. Contudo, nada parece indicar a existência de uma política pública abrangente de assistência técnica rural, que somente vai iniciar no país nos anos 1930 (EMATER-RS/ASCAR, 2005), e se consolidar a partir da década de 1950, com a adoção de diretrizes intervencionistas e difusionistas.

Especificamente no local da pesquisa, Simch (1961) descreve trabalhos efetivos em assistência técnica e extensão rural a partir dos anos 1950, com ações sendo priorizadas no combate a enfermidades dos rebanhos bovinos, equinos e ovinos, e manejo sanitário de cultivos agrícolas. Sem desconsiderar os primórdios das ações de assessoramento à pecuária e à agricultura no estado e localmente, cabe salientar, todavia, três ações importantes que iniciaram na década de 1990, e que, certamente, facilitaram as mudanças que vieram a seguir para a promoção da Agricultura Familiar, mais particularmente, o público da pecuária familiar. São elas: a instituição dos conselhos de desenvolvimento rural, a organização comunitária e as patrulhas agrícolas municipais.

Os conselhos municipais na região evoluíram desde sua criação até hoje, com a ampliação representativa da diversidade pelo assento dos representantes das associações rurais. Os dados de campo indicam que os conselhos, apesar das dificuldades inerentes aos processos de representação democrática e de especificidades locais, têm sido avaliados como órgãos atuantes e voltados para levantar fatos e encaminhar reivindicações, assim como têm influído na criação de programas locais e na discussão de políticas concebidas em instâncias superiores, de modo a beneficiar as localidades.

A criação de associações nas localidades do interior aconteceu ao longo dos anos 1990 e é considerado um processo consolidado entre os moradores das comunidades de Butiá e São Jerônimo, sendo usadas, inter alia, como instrumentos de aproximação entre técnicos e produtores e facilitadoras de fluxos de informação e conhecimento. Elas 
funcionam também como elementos basilares para a operacionalização de diversos programas importantes, tal como o das patrulhas agrícolas. Há registros de atendimento por patrulhas desde os anos 1980 e, segundo alguns informantes-chave, elas são, comparativamente ao passado, menos utilizadas hoje em dia. Mas mesmo assim, as patrulhas agrícolas ainda são avaliadas como um elemento fundamental para atender os pequenos e médios produtores, tanto nas áreas do interior, quanto naquelas ao redor das cidades.

A função estratégica chave das associações nesse programa foi se consolidando com o passar do tempo. No início, segundo relato de um agente de desenvolvimento vinculado a uma das prefeituras municipais, existiam apenas dois tratores e um operador para a condução do programa. Com a chegada de mais patrulhas agrícolas completas, com vários implementos, tornou-se necessário um número muito maior de operadores e de ações de apoio logística. Diante desse cenário, foi criado um sistema de comodato/cedência, com repasse de algumas patrulhas agrícolas para gestão das associações. Apesar de particularidades específicas entre os dois principais sistemas consultados, o de São Jerônimo e o de Butiá, ambos caminham, hoje em dia, para a delegação crescente em autogestão e autonomia das patrulhas agrícolas pelas associações rurais, sem repasse de qualquer parcela do valor arrecadado para as prefeituras, mas com aumento da responsabilidade sobre os gastos com manutenção e custeio.

Ficam evidentes, na evolução dos programas de patrulha agrícola, conquistas relevantes para o universo da agricultura familiar, com fortalecimento da capacidade de agência, exercício de habilidades coletivas para reivindicação e para solução de problemas, e capacidade operacional para implantação e condução de lavouras, pastagens, açudes e limpeza de campos. Entretanto, o segmento social dos pecuaristas familiares, entendidos e definidos como um público especial dentro da diversidade que compõe o universo da Agricultura Familiar, tem uma trajetória histórica particular nesse processo de surgimento e evolução da rede rural, o qual será tratado a partir de agora.

Partindo, principalmente, das entrevistas semiestruturadas com informantes-chave, pode-se afirmar que o trabalho com pecuária familiar iniciou na segunda metade dos anos 1990, tendo como 
principais resultados a definição de algumas estratégias prioritárias. Dentre elas, destacam-se a capacitação de extensionistas da Empresa de Assistência Técnica e Extensão Rural - Emater, na qual as equipes da Empresa Brasileira de Pesquisa Agropecuária - Embrapa Pecuária Sul e da Universidade Federal do Rio Grande do Sul - UFRGS foram convidadas a colaborar; e o estímulo à criação de programas locais de desenvolvimento nos quais a pecuária familiar fosse contemplada. Então, a partir dessas primeiras definições, o debate sobre as características e a forma de abordagem a esse público foi ganhando força na região e serviu de diretriz para o estabelecimento de um trabalho inicial de diagnóstico focado naqueles municípios onde o contingente de pecuaristas familiares era mais expressivo, concomitantemente, ao debate que ocorria em nível estadual.

Nota-se que a atividade de prospecção caracterizou o trabalho inicial na pecuária familiar, com debates no Município de São Jerônimo e o primeiro diagnóstico em Butiá na segunda metade dos anos 1990, mas a intensificação do atendimento às demandas específicas do segmento, apoiado por políticas públicas próprias (e.g. repasse de reprodutores bovinos; inseminação artificial) foi acontecer no início dos anos 2000, mesmo que antes disso muitas atividades tenham sido postas em prática para o público de pecuaristas como um todo. Esses aspectos levam a perceber que, aos poucos, foi ocorrendo uma transição em direção a exclusividade de atendimento. $O$ trecho abaixo é parte desta evidência.

Havia o trabalho, mas a gama de público envolvia médias e grandes propriedades. [...] O que é relativamente novo é o enfoque que começou a ser dado a esse público a partir daqueles enquadramentos em 2000, 2001, que nós tivemos que trabalhar com agricultura familiar. Então, ficou acertado que seria trabalhado esse produtor que tá em áreas que, muitas vezes, não tem aptidão para a agricultura, com afloramentos de rocha, muita declividade, pouca fertilidade, com áreas de 300 ha pra baixo, nessa turma da pecuária familiar, e até hoje nós trabalhamos com essa gama de público (ENTREVISTADO №16).

Desse modo, a partir dos anos 2000, gradativamente, as médias e grandes propriedades deixam de ser o público preferencial da extensão 
rural pública e começam a surgir políticas e programas para pecuaristas familiares nos municípios. Reitera-se, aqui, que tais políticas partiam da noção de que se tratava de um segmento excluído, com pouca participação política e com pouca voz em entidades de representação. A pesquisa a campo permitiu constatar que os municípios de Butiá e São Jerônimo parecem trazer exemplos bem sucedidos no que tange ao conjunto destas políticas.

Cabe salientar também, com base em informações repassadas por agentes locais, que a intervenção de políticas públicas estaduais, por exemplo, o Fundo Estadual de Apoio ao Desenvolvimento dos Pequenos Estabelecimentos Rurais - Feaper auxiliou o trabalho inicial com os pecuaristas familiares, favorecendo a aquisição de reprodutores. É relevante mencionar este tipo de financiamento, com algumas facilidades importantes de pagamento (i.e. carência e juros baixos), porque, de acordo com os dados da pesquisa, sempre houve disponibilidade de financiamento para a agricultura na região, mas, na área de pecuária, não havia crédito diferenciado para custeio, nem para o grande e médio, tampouco, para o pequeno proprietário.

Mesmo o Programa Nacional de Fortalecimento da Agricultura Familiar - Pronaf, existente desde 1997, só em 2001, passa a disponibilizar algum crédito para a pecuária; e somente nos últimos oito anos, conforme transmitido por informantes-chave, que se intensificam políticas públicas com financiamentos para a pecuária. Além dessas ações de financiamento, de repasse de recursos, muitos programas concebidos e disponibilizados localmente tiveram também intenção de introduzir novas formas de manejo dos campos e do rebanho. Um deles tem sido o melhoramento do campo nativo - $\mathrm{CN}$ e das pastagens, foco que se consolida depois que a pecuária familiar passa a público prioritário. Outro programa local, para além do crédito, foi o de Inseminação Artificial em Tempo Fixo - IATF, com destaque para os que ocorreram em Butiá e São Jerônimo. No entanto, há descontinuidades, uma vez que os mais longevos duraram apenas dois anos consecutivos. 
Segundo um agente de desenvolvimento local, as primeiras motivações para a estruturação de ações para a pecuária familiar recaíam sobre a questão da padronização dos rebanhos, e o caminho escolhido para perseguir este objetivo, no início dos anos 2000, foi a operacionalização de um programa de inseminação artificial, cujas primeiras atividades ocorreram na localidade da Quitéria, São Jerônimo. Entendia-se, nessa época, que a padronização dos rebanhos refletiria positivamente na comercialização de bovinos para abate e despertaria o interesse dos compradores em buscar lotes de animais de diferentes criadores, ainda que em localidades distantes, fato que não ocorria até então.

O começo das ações era dirigido aos pequenos criadores de ovinos para aprimoramento do manejo dos animais, avanços sanitários e melhoramento genético. No início do trabalho, os produtores encontravam-se desmotivados com a ovinocultura e as práticas para lidar com os animais estavam inadequadas. Para motivá-los, uma das estratégias foi a instalação do concurso de cordeiros. Para tanto, a sinergia entre diversas entidades e produtores foi fundamental, tendo reflexos significativos na melhoria de alguns aspectos técnicos, por exemplo, a genética dos cordeiros, ganho de peso, qualidade da carne, da lã e o próprio manejo dos rebanhos.

A inclusão do público da pecuária familiar como beneficiário do Pronaf redundou na possibilidade de uma gama de financiamentos, e foi importante, entre outras coisas, para substituir a linha estadual de repasse de touros do Feaper que tinha sido interrompida em 2002. A promulgação da Lei 13.505 e o Decreto 48.515 que instituiu e regulamentou, respectivamente, o Programa Estadual de Fortalecimento da Pecuária de Corte Familiar - PECFAM são outros exemplos da evolução das ações. Já em 2011, ressalta-se a criação da Secretaria Estadual de Desenvolvimento Rural - SDR e, com isto, o retorno, no ano seguinte, da linha Feaper para financiamentos diversos aos pecuaristas familiares. Nos anos 2010, iniciam também programas locais bem sucedidos e que alcançaram repercussão regional, servindo de exemplo para a disseminação de políticas e programas contextualizados em diferentes espaços. Ou seja, a partir das ações iniciais de organização comunitária, prospecção, diagnóstico, capacitações e debates houve 
avanços significativos, chegando a inúmeras práticas e trajetórias, hoje, estabelecidas. Essas incidem em diversas dimensões da vida nas comunidades locais, com repercussões no escopo regional, justamente com base nisto é que se pode afirmar que uma rede rural foi sendo engendrada no contexto da pecuária familiar da região Centro Sul do RS.

\section{Dos Arranjos Multi-institucionais às Práticas e Trajetórias}

Distinguem-se, nessa seção, arranjos, como o Conselho Regional de Desenvolvimento - COREDE e o Território Centro Sul; entidades, como a SDR, Emater Regional, Ministério do Desenvolvimento Agrário MDA, Secretaria de Estado de Agricultura e Pecuária - SEAPA; e linhas de financiamento, como aquelas contidas no Pronaf, Feaper, Programa Mais Ovinos no Campo, e as emendas parlamentares, cuja abrangência incide em um escopo regional destacado na rede de desenvolvimento rural da pecuária familiar.

O trabalho de campo identificou o COREDE Centro-Sul como um arranjo institucional importante, ainda que não tenha emergido como uma ação local. Os COREDEs foram criados pela Lei 10.283/1994 e se orientam pelo princípio de pensar e promover as políticas/ações através do prisma regional em fóruns democráticos, o que potencialmente instiga movimentos de coalizão entre atores locais de diferentes municípios, mas com características e objetivos comuns, e maior eficiência na alocação dos recursos (RIO GRANDE DO SUL, 2015a). Além disso, o conjunto de municípios que compõem o COREDE Centro Sul tem sido abordado como um território pela SDT/MDA dentro do Programa de Desenvolvimento Sustentável dos Territórios Rurais.

Desse modo, foi a partir de assembleias de discussão e definição de prioridades territoriais que se dispararam os gatilhos da mobilização e da articulação coletiva intermunicipal que resultaram na aprovação do Projeto de Desenvolvimento da Ovinocultura da Região Centro Sul. Como consequências dessa aprovação, desencadearam-se acontecimentos marcantes, como a fundação de Associação Regional de Criadores, a aprovação de financiamentos, com recursos federais ${ }^{7}$, para

\footnotetext{
7Programa de Desenvolvimento Sustentável de Territórios Rurais através da SDT/MDA para o Território Centro-Sul.
} 
concretização de objetivos comerciais dos ovinocultores, a proposta de constituição de uma Marca Coletiva, um processo reflexivo sobre gargalos e potencialidades da cadeia produtiva de carne ovina e o papel do segmento social dos pecuaristas familiares neste contexto.

A SDR tem sua atuação relacionada com o trabalho em pecuária familiar no estado e na região, cujas diretrizes estão definidas no Programa PECFAM. Conforme as linhas prioritárias desse Programa, o fortalecimento da pecuária familiar se daria através de ações de qualificação de produtores e técnicos; implantação de Unidades Demonstrativas-UDs, assistência técnica; melhoramento de campo nativo; troca-troca de sementes; melhoramento genético e sanitário do rebanho; crédito para a pecuária familiar; e criação de canais de comercialização (RIO GRANDE DO SUL, 2012a).

De acordo com um agente regional, existia no início da atuação da SDR, a quantia de R\$200.000 para a confecção e operação de uma política pública para a pecuária familiar. Diante desse desafio, iniciaram-se as discussões para a definição da melhor forma de aplicar esse montante de recursos sem que seus resultados ficassem no âmbito individual de atendimento. Nesse processo de elaboração da política, a qual se materializou no Programa Fortalecimento da Pecuária Familiar (RIO GRANDE DO SUL, 2012a), se envolveram inicialmente a SDR e a Emater e, posteriormente, a equipe de pesquisadores da Embrapa Pecuária Sul. Essa parceria foi oficialmente instituída através do Termo de Cooperação 3729/2012, concebido com o objetivo de implantar o Programa Estadual de Desenvolvimento da Pecuária de Corte Familiar Lei 13.515/2010, que estipulava, entre outros compromissos, ações de capacitação para pecuaristas e técnicos, fomento a mercados diferenciados, e apoio à implantação e manutenção das Unidades de Experimentação Participativa em Pecuária Familiar - UEPs (RIO GRANDE DO SUL, 2012b), que se tornaram a estratégia preponderante na operacionalização do PECFAM na região Centro Sul.

No primeiro ano de atuação da SDR, foi disponibilizado um financiamento no limite de $R \$ 10.000$ por pecuarista para a implantação das UEPs em Pecuária Familiar, cujo objetivo geral envolvia a manutenção do $\mathrm{CN}$, o que não queria dizer que o financiamento tinha 
que ser exclusivamente para ações sobre o campo nativo, mas ele deveria promover melhoramento do recurso nativo.

As duas UEPs em Butiá são as mais antigas, datadas de 2012, com a particularidade positiva de ter ajudado na sucessão familiar, já que os filhos têm uma atuação destacada ao lado dos pais na condução das propriedades. Posteriormente, em São Jerônimo, o produtor inicialmente beneficiado de forma individual, mediante discussões locais, optou, em função disso, pelo financiamento de uma balança e a construção em mutirão de um centro de manejo, ambos instalados na sede da associação comunitária, para uso coletivo no manejo dos rebanhos e nas operações de compra e venda de gado. Em alguns outros municípios da região, as UEPs ainda se encontravam em fase de implantação na época da pesquisa.

Outros signos da atuação regional da SDR são os repasses de reprodutores, por meio do Programa Aquisição de Reprodutores para Pecuária Familiar (RIO GRANDE DO SUL, 2014a); os conjuntos de inseminação artificial para atendimento a grupos de produtores, via Programa Melhoramento Genético (RIO GRANDE DO SUL, 2014b); e os programas troca-troca de sementes de forrageiras, milho e feijão. Em 2014, foram 19 touros financiados para produtores de São Jerônimo e Butiá; e Dom Feliciano opera os conjuntos de IA.

O Escritório Regional da Emater é outra entidade com atuação na promoção da pecuária familiar, em vinculação com atores locais, como as Prefeituras Municipais, Associações de Produtores, Sindicatos e os Escritórios Municipais. Muito já foi dito sobre a atuação dessa entidade na parte inicial deste texto, evidenciando que a identificação, o diagnóstico, e a definição da melhor abordagem aos pecuaristas familiares na região foram iniciados pela equipe regional de extensionistas.

O MDA aparece na atuação regional por ser, à época, o ministério responsável por programas imprescindíveis para a Agricultura Familiar, que estavam incidindo ou tinham potencial futuro na promoção da pecuária familiar regional. O Programa de Desenvolvimento Sustentável de Territórios Rurais provocou, como mencionado acima, a mobilização inicial em escopo mais amplo, congregando um conjunto de municípios na defesa de prioridades comuns. Os programas Pronaf e Mais Alimento 
têm atendido os pecuaristas familiares; o primeiro desde o início dos anos 2000; e o segundo, mais recentemente, na aquisição de máquinas, implementos e veículos. O Programa de Aquisição de Alimentos - PAA e - Programa Nacional de Alimentação Escolar - PNAE ainda tinham implementação tímida ${ }^{8}$, com parte significativa do abastecimento obrigatório proveniente da agricultura familiar sendo atendido por grupos de produtores e associações de outros municípios da região, como Guaíba e Sertão Santana (ENTREVISTADO N² 24). Na época da pesquisa, a avaliação era de que havia potencial futuro destes programas na medida em que a Associação Regional de Ovinocultores pudesse viabilizar, coletivamente, o transporte, o abate em frigorífico, e a marca.

Apesar de os pecuaristas familiares não serem o segmento social prioritário para a SEAPA, dois programas sob responsabilidade da Fundação Estadual de Pesquisa Agropecuária - Fepagro, entidade vinculada a esta pasta, incidiram regionalmente. Um deles é o programa de inseminação artificial, denominado Dissemina, levado adiante no bojo do Programa de Valorização da Carne Gaúcha, que atende produtores de bovinos de corte e também de leite enquadrados pela Declaração de Aptidão ao Pronaf - DAP (RIO GRANDE DO SUL, 2015b). O segundo programa vinculado à SEAPA é o Programa Estadual de Correção do Solo que forneceu calcário a preço subsidiado a produtores considerados descapitalizados, enquadrados pela DAP como agricultores ou pecuaristas familiares, e cujos solos necessitavam de correção da acidez. Se apurou a aplicação deste programa, nos últimos anos, em Butiá, Arroio dos Ratos, Charqueadas, Sertão Santana, Dom Feliciano, Camaquã, Cristal e Cerro Grande do Sul.

Quanto às linhas de financiamento, destaca-se, em abrangência regional, o Pronaf, sob a responsabilidade do MDA, que tem atendido os pecuaristas familiares, nas modalidades custeio e investimento, com condições diferenciadas e condizentes com as características deste segmento. Muitos mutirões e articulações entre atores locais (Prefeituras Municipais, Sindicatos de Trabalhadores Rurais - STRs, Associações

8No município de Butiá, a integralidade de aquisições da AF local atingiu, em 2014, somente $8 \%$ do montante total destinado à merenda escolar. A legislação do PNAE exige no mínimo 30\% (ENTREVISTADO N²4). 
Rurais, Agentes financeiros e Emater) foram relatados no trabalho de campo para viabilizar a aplicação deste programa nas comunidades rurais, tendo por objetivo a implantação de lavouras, de pastagens, aquisição de insumos agrícolas e veterinários, compra e retenção de matrizes e reprodutores, bem como para construção de açudes de dessedentação e irrigação.

O Programa Mais Alimento Produção Primária é uma linha de crédito do Pronaf, e tem incidido na região, a partir dos anos 2010, para a aquisição de máquinas agrícolas, especialmente tratores, implementos e veículos. São também objetos financiáveis pelo programa os sistemas de irrigação e as estruturas de armazenagem, mas o trabalho de campo não identificou créditos para estes fins.

O Feaper, sob a responsabilidade da SDR, tem destaque regional no financiamento das UEPs, repasse dos reprodutores bovinos, conjuntos de inseminação artificial, programas troca-troca de milho, feijão e forrageiras com condições de pagamento muito especiais e facilitadas para os pecuaristas familiares. O Programa Conjuntos de IA, com também condições muito especiais para quitação, permite a aquisição do botijão de resfriamento, que é o item mais caro, e materiais como luvas e pipetas, com possibilidade de verba complementar até o limite de $\mathrm{R} \$ 4.000$ l para compra de sêmen. 
O Programa Mais Ovinos no Campo, sob a responsabilidade da SEAPA, se insere no conjunto de iniciativas do Programa Estadual de Desenvolvimento da Ovinocultura, tendo como foco a retenção e/ou aquisição de fêmeas ovinas, ovelhas e cordeiras, dirigido a criadores de qualquer porte, visando o aumento do rebanho riograndense, e o aumento da oferta de carne e lã de qualidade (RIO GRANDE DO SUL, 2015b).

As emendas parlamentares foram identificadas com incidência pontual em comunidades e municípios, mas, no cômputo geral, podem ser consideradas como de abrangência regional. Apesar de toda a polêmica que envolve este instrumento, os créditos liberados têm beneficiado os pecuaristas familiares por meio do incremento na capacidade das patrulhas agrícolas, por aquisição de novos tratores e implementos, e melhoria do atendimento em saúde, por reforma e ampliação de leitos em hospitais municipais.

A caminhada rastreada nas linhas deste artigo envolve inter alia práticas e trajetórias distintas que podem ser segmentadas por fases temporais, as quais, em conjunto, contribuem para a percepção do andamento da rede rural (Quadro 1). O que foi levantado e descrito salienta o processo de emergência da rede rural como coevolutivo, na medida em que há transformações associada ao manejo de recursos naturais e produtivos que, todavia, reciprocamente articulados com mudanças de ordem institucional e política, além de outros possíveis entrelaçamentos. A complexidade da rede rural em questão não é fácil de representar esquematicamente em uma figura. Contudo, a Figura 2 apresenta um conjunto de atores, atividades, conexões, cadeias, transações e recursos que estão entrelaçados no espaço protegido e na região Centro-Sul como um todo.

Os componentes entrelaçados em dinâmicas de coprodução e coevolução conferem aspectos únicos à rede rural de desenvolvimento da pecuária familiar da região Centro-Sul, pois são resultado de relacionamentos e processos adaptativos entre atores e natureza que se moldam no tempo e no local. As práticas e trajetórias foram e estão sendo propostas, debatidas, executadas e redimensionadas a partir de contingências, pressões, oportunidades e percepções dos atores sociais na relação com o ambiente circundante, ou seja, com o contexto 
específico, que imputa exclusividade à rede, o que não significa seu isolamento. 
Quadro 1. Evolução das práticas e trajetórias em pecuária familiar -

Região Centro-Sul

\begin{tabular}{|c|c|c|c|c|}
\hline Até 1998 & $\begin{array}{c}\text { Fase 1998- } \\
2001\end{array}$ & $\begin{array}{c}\text { Fase } 2001- \\
2002\end{array}$ & Fase $2002-2010$ & Fase $2010-2015$ \\
\hline $\begin{array}{l}\text {-Melhoramento } \\
\text { de CN e } \\
\text { Pastagens; } \\
\text {-Atendimento } \\
\text { à grandes, } \\
\text { médios e } \\
\text { pequenos; } \\
\text {-Carência de } \\
\text { políticas e } \\
\text { programas de } \\
\text { apoio. } \\
\text {-Criação das } \\
\text { associações } \\
\text { comunitárias } \\
\text {-Criação dos } \\
\text { conselhos } \\
\text { municipais } \\
\text {-Patrulhas } \\
\text { agrícolas; } \\
\text {-Programa } \\
\text { FEAPER - troca- } \\
\text { troca. }\end{array}$ & $\begin{array}{l}\text {-Prospecção, } \\
\text { estudo e debate } \\
\text { sobre Pecuária } \\
\text { Familiar; } \\
\text {-Transição do } \\
\text { foco - } \\
\text { Exclusividade } \\
\text { na PF; } \\
\text {-Capacitação } \\
\text { de técnicos; } \\
\text {-Seminário } \\
\text { sobre Pecuária } \\
\text { Familiar. } \\
\text {-Melhoramento } \\
\text { de CN e } \\
\text { Pastagens; } \\
\text {-Estímulo à } \\
\text { criação de } \\
\text { programas } \\
\text { locais e } \\
\text { estaduais; } \\
\text {-Criação das } \\
\text { associaçães } \\
\text { comunitárias } \\
\text {-Patrulhas } \\
\text { agrícolas; } \\
\text {-Programa } \\
\text { FEAPER - troca- } \\
\text { troca. }\end{array}$ & $\begin{array}{l}\text {-Diagnósticos } \\
\text { DRPs Pecuária } \\
\text { familiar } \\
\text {-Programa } \\
\text { FEAPER - } \\
\text { repasse de } \\
\text { touros e troca- } \\
\text { troca; } \\
\text {-Definição do } \\
\text { público - } \\
\text { Pecuária } \\
\text { Familiar; } \\
\text {-Melhoramento } \\
\text { de CN e } \\
\text { Pastagens; } \\
\text {-Patrulhas } \\
\text { agrícolas. }\end{array}$ & $\begin{array}{l}\text {-Concurso de } \\
\text { cordeiros. } \\
\text {-Jantar do } \\
\text { Cordeiro, Uva e } \\
\text { Vinho; } \\
\text {-Programa Repasse } \\
\text { de Carneiros; } \\
\text {-Programa FEAPER } \\
\text { - troca-troca } \\
\text {-Programas locais: } \\
\text { IA - melhoramento } \\
\text { genético de } \\
\text { bovinos; sanidade } \\
\text { dos rebanhos; e } \\
\text { aprimoramento } \\
\text { manejo geral. } \\
\text {-Melhoramento de } \\
\text { CN e Pastagens; } \\
\text {-PRONAF para } \\
\text { Pecuária Familiar: } \\
\text { matrizes, } \\
\text { reprodutores, } \\
\text { retenção de } \\
\text { animais, } \\
\text { pastagens. } \\
\text {-Programa Mais } \\
\text { Alimento } \\
\text {-Crédito rural para } \\
\text { pecuária em geral; } \\
\text {-Patrulhas } \\
\text { agrícolas; } \\
\text {-Grupo Fia e Tece. }\end{array}$ & $\begin{array}{l}\text {-Lei } 13.505 \text { e } \\
\text { Decreto 48.515. } \\
\text { Programa PECFAM } \\
\text {-Criação da SDR; } \\
\text {-Programa } \\
\text { FEAPER - repasse } \\
\text { de touros, troca- } \\
\text { troca; } \\
\text {-Instalação de } \\
\text { UEPs } \\
\text {-Melhoramento } \\
\text { de CN e } \\
\text { Pastagens; } \\
\text {-Programa } \\
\text { Dissemina e } \\
\text { correção de solo - } \\
\text { SEAPA/FEPACRO } \\
\text {-Conjuntos de IA } \\
\text { - SDR } \\
\text {-Remate Regional } \\
\text { da PF } \\
\text {-Feiras de Ovinos } \\
\text {-Concurso de } \\
\text { cordeiros. } \\
\text {-Jantar do } \\
\text { Cordeiro, Uva e } \\
\text { Vinho; } \\
\text {-Programas de } \\
\text { Repasse de } \\
\text { Carneiros } \\
\text {-Disseminação de } \\
\text { Programas Locais; } \\
\text {-Fundação da } \\
\text { Associação } \\
\text { Regional de } \\
\text { Ovinocultores - } \\
\text { Marca Coletiva; } \\
\text {-PRONAF e Mais } \\
\text { Alimento } \\
\text { (PRONAF); } \\
\text {-Patrulhas }\end{array}$ \\
\hline
\end{tabular}




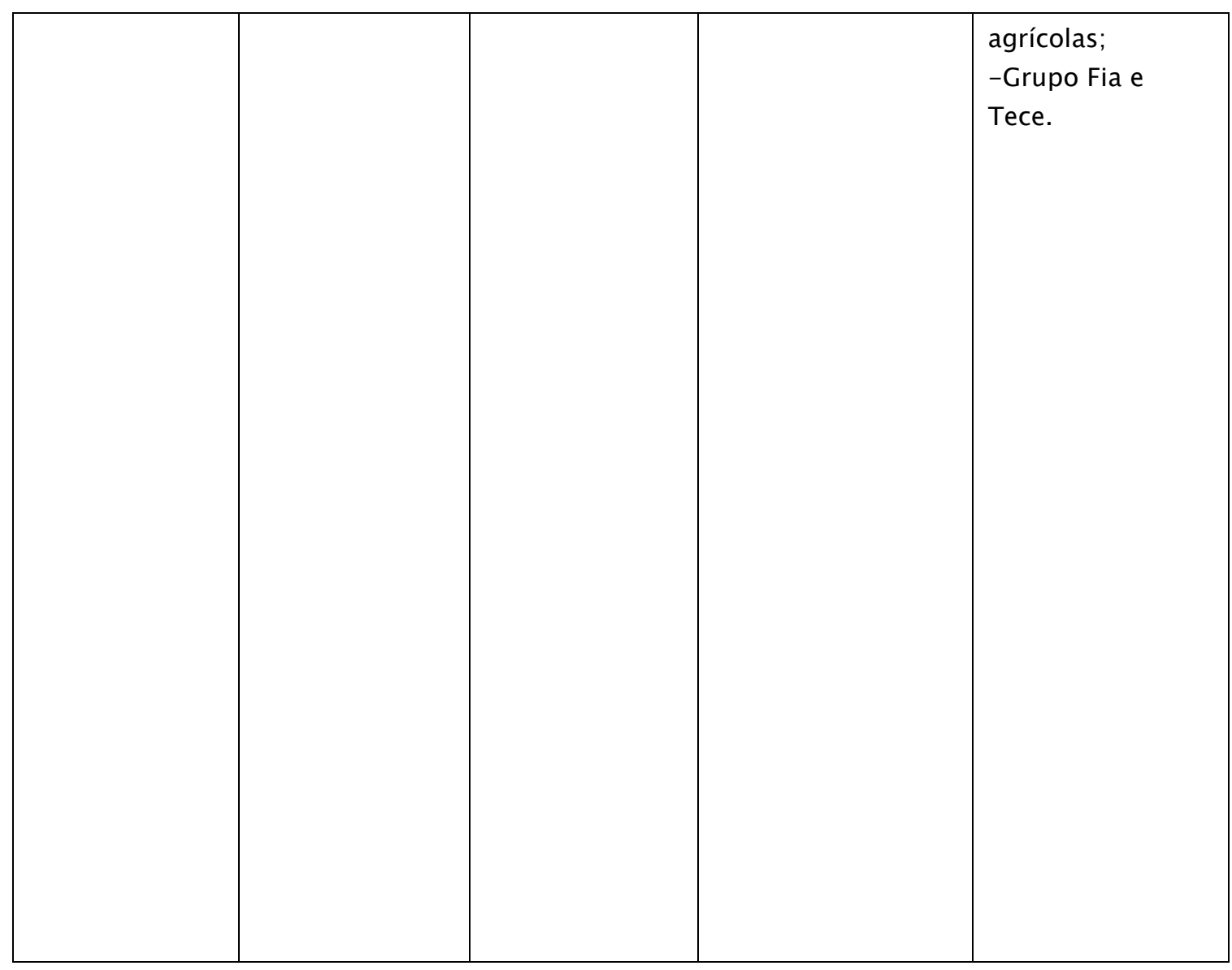

Fonte: elaborado a partir de levantamentos da pesquisa (2015). 
Figura 2. Representação da rede rural de desenvolvimento da pecuária familiar na região Centro Sul-RS

\begin{tabular}{|l|}
\hline Concurso de Cordeiros \\
Repasse de Carneiros \\
Feira Assistida de Ovinos. \\
Jantar do Cordeiro, Uva e \\
Vinho. \\
Conjunto geral de ações e \\
programas em pecuária \\
familiar \\
Artesanato.
\end{tabular}

\begin{tabular}{|c|c|}
\hline & COREDE e Território \\
\hline $\begin{array}{c}\text { Remate Regional da Pecuária Familiar } \\
\text { Marca Coletiva } \\
\text { Associação Regional de Ovinocultores } \\
\text { Os pecuaristas, os rebanhos, e o campo. }\end{array}$ & $\begin{array}{l}\text { SDR-Feaper } \\
\text { MDA-Pronaf, Mais } \\
\text { Alimentos } \\
\text { Emater Regional } \\
\text { SEAPA-Dissemina }\end{array}$ \\
\hline & $\begin{array}{l}\text { Calcário e Mais Ovinos } \\
\text { Emendas parlamentares }\end{array}$ \\
\hline
\end{tabular}



\begin{tabular}{|l|l|l|}
\hline Pecuaristas familiares e associações & & ABPHPC \\
\hline Escritórios da EMATER & & Reponte Escritório Rural \\
\hline STRs & & Abatedouro e Comércio de Carnes \\
\hline Sec. Munic. Agricultura - Pref. Municipais & & Associação de Artesãs - Grupo Fia e Tece \\
\hline IVZs & & CMDR \\
\hline SRs & & UEPs \\
\hline Instituições bancárias & & \\
\hline
\end{tabular}

Fonte: elaborado sobre mapa do COREDE Centro-Sul (RIO GRANDE DO SUL, 2015a). 
Para entender melhor os componentes da Rede Rural, é necessário que se diga que o quadro superior à direita reúne as entidades, arranjos, programas e políticas extralocais (e.g. SDR, Território CentroSul, Programa Mais Ovinos, Pronaf). E, no lado esquerdo, são listadas algumas práticas e trajetórias locais (e.g. Repasse de Carneiros, Feira) concebidas como resultado das dinâmicas que ocorrem no espaço protegido da pecuária familiar. Ao centro da representação, estão as práticas e trajetórias de caráter regional (e.g. Remate, Marca), arranjos organizacionais decorrentes do debate e colisões entre atores (e.g. Associação) e recursos intrínsecos e característicos próprios da rede (e.g. pecuaristas, rebanhos, campo nativo). Os pecuaristas familiares e suas organizações são atores centrais da rede rural, e estão presentes em todos os municípios; bem como alguns de seus principais recursos endógenos, representados pelos rebanhos de bovinos, de ovinos e pelas superfícies campestres, unidades essenciais da coprodução pecuária e seus derivados. Assim, práticas, trajetórias e atores, desde uma perspectiva espacializada, criam um emaranhado que, na Figura 2, também é percebido pelas interligações entre os atores (círculos coloridos) posicionados na representação do território.

As práticas e trajetórias mais representativas no espaço protegido de promoção da pecuária familiar, bem como no âmbito mais abrangente da região Centro-Sul são a associação de ovinocultores, a feira de ovinos, o repasse de carneiros e o remate da pecuária familiar. São também emblemáticos o Concurso, o Jantar do Cordeiro e o artesanato em lã ${ }^{9}$, bem como os atores, arranjos, entidades e financiamentos. Entretanto, sob a proteção deliberada no espaço da pecuária familiar, desenvolve-se uma multiplicidade de ações que vão entrando na rotina da vida dos criadores, das suas famílias, das organizações e dos demais atores. As particularidades das relações estabelecidas para o interior do espaço protegido, então, extrapolam em muito a restrita dimensão técnico-produtiva, constituindo-se em importantes alicerces para os desdobramentos da rede rural. Desse modo, as ações de assistência técnica, de extensão rural, de atenção à saúde, na educação, nos investimentos em infraestrutura, na seguridade social, e, sobretudo, de participação democrática dos pecuaristas familiares incidem total ou parcialmente sobre os desdobramentos da

9Para detalhes sobre as práticas e trajetórias ver Nicola (2015). 
rede que, significam, em última análise, o próprio processo de desenvolvimento rural.

A Figura 3 mostra uma densidade de atores, ações, projetos e programas que, de certa maneira, garantem a conformação do espaço protegido, concentrando-se em três vertentes que podem ser assinaladas, em linhas gerais, como os três eixos principais da rede rural de desenvolvimento na pecuária familiar. Um dos eixos aglutina as atividades relacionadas com investimentos, públicos e/ou privados, inclusive dos próprios agricultores, em infraestrutura de estradas através de patrulhas mecanizadas; telefonia; estruturas de saúde; transporte público no interior; transporte escolar e escolas rurais. Os temas reunidos nesse eixo são, geralmente, motivo de grande preocupação para as famílias rurais e geram, proporcionalmente, mobilizações coletivas, via associações e conselhos municipais, ou outros mecanismos reivindicatórios.

No segundo eixo, observa-se a canalização de esforços e recursos na melhoria genética dos rebanhos e no aperfeiçoamento das práticas de manejo do $\mathrm{CN}$ e dos animais, englobando os programas municipais e estaduais de IA; os repasses estaduais e municipais de reprodutores; os concursos de cordeiros; as visitas, reuniões técnicas, os cursos de formação; e as UEPs. Já, uma terceira linha de ação se caracteriza pela agregação de valor aos produtos e a tentativa de ampliar a governabilidade de mercados existentes e/ou a criação de novos. O incentivo à produção de leite, as feiras de produtos coloniais e artesanais, os projetos de fomento (artesanato, leite, frutas, peixes e mel), as feiras de ovinos, o remate regional da pecuária familiar e as trajetórias em busca do desenvolvimento da ovinocultura na região Centro-Sul são exemplos nesta linha.

Figura 3. Representação dos atores, ações e programas no espaço protegido da pecuária familiar 


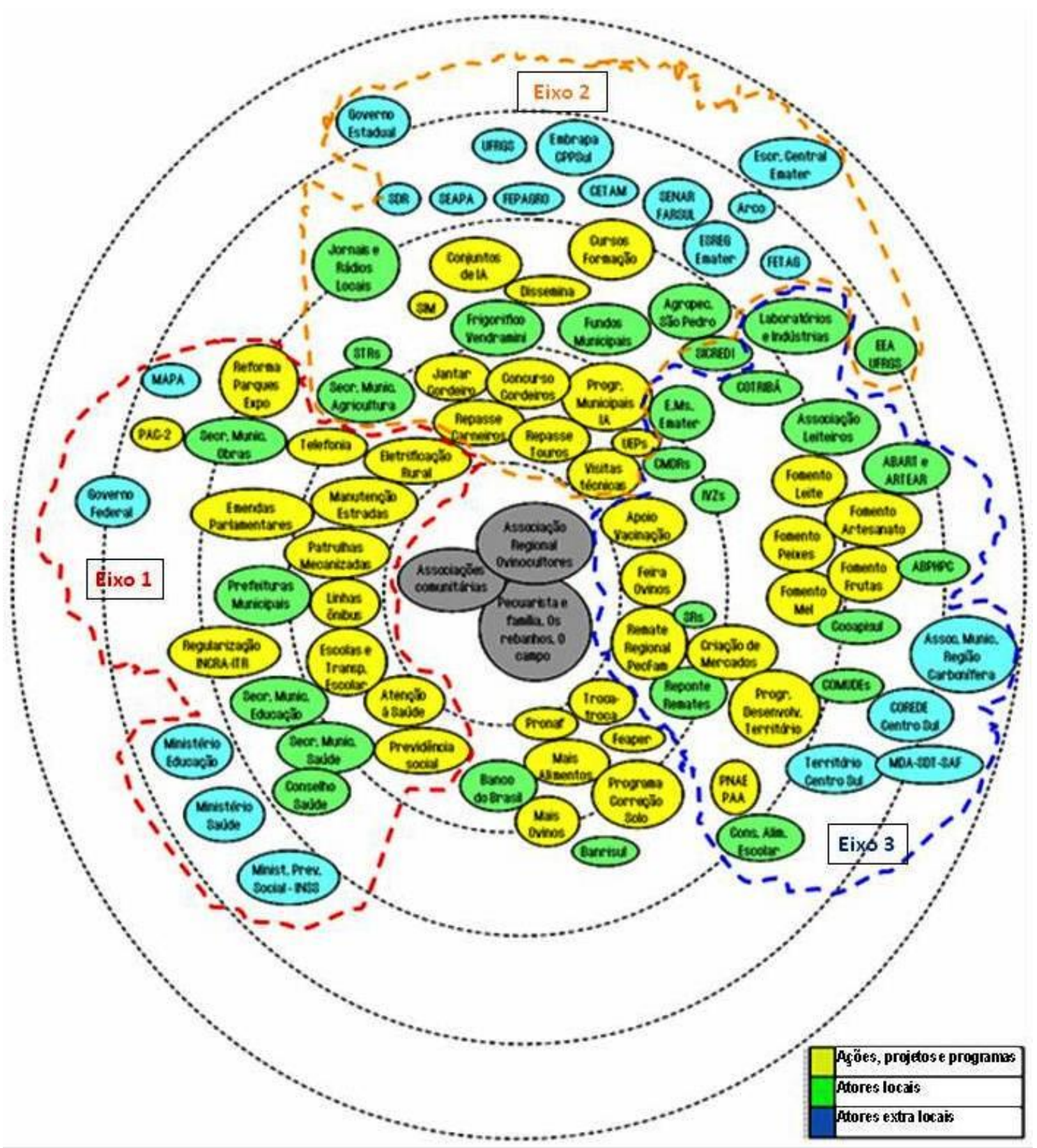

Fonte: elaborado a partir de levantamentos da pesquisa (2014/2015).

Além dos três eixos de operação da rede identificados no diagrama, há também o conjunto de políticas e programas de apoio que disponibilizam, entre outras coisas, recursos financeiros e os respectivos agentes financeiros. Particularmente, nos eixos dois e três, destacam-se o Pronaf (custeio; investimento; Mais Alimentos), Feaper (Troca-Troca de sementes; calcário), o Programa de Desenvolvimento dos Territórios, os Fundos Municipais, e o Programa Mais Ovinos.

As iniciativas e conexões que definem estratégias; corrigem rumos; alimentam expectativas; e/ou geram práticas e trajetórias são compreendidas como as ações de gestão levadas adiante por múltiplos 
atores no espaço protegido. Porém, a evolução das iniciativas e conexões diversas parece estar criando, tendencialmente, um ambiente profícuo para a emergência de coisas novas com repercussão na região Centro-Sul, conectando atores e recursos municipais em desdobramentos, talvez indicando ampliação da rede.

Nesse sentido, essa dinâmica local parece se constituir como algo semelhante àquilo que Moors et al (2004) denominam de estímulo à "criação de novidades". No entanto, a escalada de algumas novidades em direção ao âmbito regional, somente tem sido possível pela atuação de atores sociais que as nutrem, as protegem e maturam, em um processo de transposição das fronteiras locais. Desse modo, seguindo as argumentações de Oostindie e Broekhuizen (2008), admite-se que o espaço protegido é a mais importante unidade para o fortalecimento da rede rural de desenvolvimento da pecuária familiar da região Centro Sul. Em outras palavras, o fortalecimento da rede rural depende da proteção do espaço onde as novidades e mudanças são pensadas e postas em prática.

\section{Considerações finais}

O artigo buscou caracterizar e elucidar como recursos endógenos, recursos financeiros, atividades produtivas, tecnologias e as ações dos atores se articulam para compor a rede rural de desenvolvimento da pecuária familiar na região Centro-Sul do RS. Fica evidenciado que a rede articula o surgimento de novos programas e políticas públicas, a conexão entre múltiplos atores, o estabelecimento de fluxos de informações, de conhecimento e de transações, além de diferentes combinações de recursos disponíveis localmente ou aportados exogenamente. Tanto as práticas e trajetórias que apresentam uma abrangência mais restrita quanto aquelas que envolvem um escopo regional são resultado de um rearranjo de recursos existentes e estão contextualizadas por características locais e repertórios culturais em um ambiente de enraizamento de instituições que têm direcionado seus esforços e haveres para o atendimento de um segmento vulnerável específico. Por isso, argumenta-se que o espaço protegido estabelecido para gestar certas mudanças na pecuária familiar na região Centro-Sul pode vir a repercutir para outros locais próximos, em uma direção que, 
pelo menos, supostamente poderá impactar o desenvolvimento regional. 
Sobreleva também a face transicional intrínseca das redes rurais, na medida em que os pecuaristas familiares foram transformados de atores marginalizados em 50 anos de modernização da agricultura, em atores relevantes no transcurso das últimas duas décadas. O caráter contracorrente da rede rural da pecuária familiar se expressa pela valorização de recursos endógenos fortemente vinculados aos aspectos histórico-culturais e ao ambiente local, e por se constituir como uma importante via alternativa às outras trajetórias de desenvolvimento presentes e em evolução na região, mas assentadas sobre recursos exógenos, como são os casos da silvicultura e o cultivo da soja. Nesse sentido, a rede rural, ao estabelecer uma dinâmica de desenvolvimento rural, guarda importante potencial de mudança do regime sociotécnico prevalente na pecuária e na agricultura.

\section{REFERÊNCIAS}

EMATER. 50 Anos de Extensão Rural no Rio Grande do Sul. Porto Alegre: EMATER-RS/ASCAR, 2005.

EMATER. Estudo de Situação. Escritório Municipal de Butiá. Butiá: EMATER/RS, $2012 \mathrm{a}$.

EMATER. Plano Operativo Municipal de ATER. Ano 2013. Escritório Municipal de Butiá. Butiá: EMATER/RS, 2012b.

EMATER. Relatório Municipal. Atividades de Assistência Técnica e Extensão Rural (ATER) de 2012. Escritório Municipal de Butiá. Butiá: EMATER/RS, 2012c.

EMATER. Estudo de Situação. Escritório Municipal de São Jerônimo. São Jerônimo: EMATER/RS, 2013.

BUREAU VERITAS CERTIFICATION. Relatório de Auditoria. CMPC Celulose Riograndense Ltda. Rio de Janeiro: Bureau Veritas Certification, 2010. Disponível em: <http://www.bureauveritascertification.com.br> . Acesso em: 29 maio 2015. 
BUTIÁ. Prefeitura Municipal. Plano Ambiental Municipal. Butiá: Secretaria Municipal de Agricultura e Proteção ao Meio Ambiente, 2009.

FEE. De Província de São Pedro a Estado do Rio Grande do Sul - Censos do RS 1803-1950. Porto Alegre: FEE, 1981. 330 p.

FEE. Perfil Socioeconômico RS - COREDES. Porto Alegre: FEE, 2013. Disponível em: <http://www.fee.rs.gov.br> . Acesso em: 29 maio 2015.

GEELS, F.W. Understanding system of innovation: a critical literature review and a conceptual synthesis. In: ELZEN, B.;GEELS,F.W.;GREEN,K. System Innovation and the Transition to Sustainability: theory, evidence and policy. Cheltenham: Northampton: Edward Elgar, p. 19-47, 2004.

IBGE. Censo Agropecuário 2006. IBGE, 2006. Segunda Apuração.

Disponível em: <http://www.ibge.gov.br>. Acesso em: 24 maio 2015.

IBGE. Pesquisa da Agricultura Familiar. IBGE, 2009.

Disponível em: <http://www.ibge.gov.br>. Acesso em: 2 mar. 2014.

IBGE. Censo Demográfico 2010. IBGE, 2010.

Disponível em: <http://cidades.ibge.gov.br>. Acesso em: 16 mar. 2014.

IBGE. Pesquisa Pecuária Municipal.Produção Agrícola Municipal. IBGE, 2013. Disponível em: <http://www.sidra.ibge.gov.br>. Acesso em: 2 maio 2015.

KARNOPP, E. Repensando o Desenvolvimento Rural no Contexto Territorial da Agricultura Familiar: Estudos de Casos. Redes. Santa Cruz do Sul, v. 19 Ed. Especial, p. 139-152, 2015.

MARQUES, F.C. Nicho e novidade: nuanças de uma possível radicalização inovadora na agricultura. In: SCHNEIDER, S.; GAZZOLA, M. Os atores do desenvolvimento rural: perspectivas teóricas e práticas sociais. Porto Alegre: Editora da UFRGS, p.189-204, 2011. 
MARSDEN, T.; PLOEG, J. D. van der. Some final reflections on Rural Social and Spatial Theory. In: PLOEG, J. D. van der; MARSDEN, T. Unfolding Webs: The Dynamics of Regional Rural Development. Amsterdam: Royal Van Gorcum, p. 225-234, 2008.

MOORS, E.; RIP, A.; WISKERKE, J.S.C. The dynamics of innovation: a multi-level co-evolutionary perspective. In: WISKERKE, J.S.C.; PLOEG, J.D. van der. Seeds of Transitions. Assen: Royal Van Gorcum, p. 31-56, 2004.

NABINGER, C.; CARVALHO, P.C.F.; DALL'AGNOL, M. Pastagens no ecossistema de clima subtropical. In: REUNIÃO ANUAL DA SOCIEDADE BRASILEIRA DE ZOOTECNIA, 42., 2005, Goiânia. Anais... Goiânia: SBZ, v. 1. p. 1-20, 2005.

NICOLA. Marcelo Porto. Espaço Protegido e Desenvolvimento Rural: práticas e trajetórias na pecuária familiar da região Centro Sul do Rio Grande do Sul, 2015. 239 f. Tese (Doutorado em Desenvolvimento Rural) - Faculdade de Ciências Econômicas. Universidade Federal do Rio Grande do Sul, Porto Alegre, 2015.

OOSTINDIE, H.; BROEKHUIZEN, R.V. The dynamics of novelty production. In: PLOEG, J. D. van der; MARSDEN, T. Unfolding Webs: The Dynamics of Regional Rural Development. Amsterdam: Royal Van Gorcum, p. 68-86, 2008.

PLOEG, J. D. van der. et al. Rural Development: from Practices and Policies towards Theory. Sociologia Ruralis. Wageningen, v. 40, n. 4, p. 391-408, 2000.

PLOEG, J. D. van der et al. On regimes, novelties and co-production. In: WISKERKE, J.S.C.; PLOEG, J.D. van der. Seeds of Transitions. Assen: Royal Van Gorcum, p. 1 - 30, 2004. 
PLOEG, J. D. van der et al. Towards a Framework for Understanding Regional Rural Development. In: PLOEG, J. D. van der; MARSDEN, T. Unfolding Webs: The Dynamics of Regional Rural Development. Amsterdam: Royal Van Gorcum, p. 1-28, 2008.

PLOEG, J. D. van der. Camponeses e Impérios Alimentares: lutas por autonomia e sustentabilidade na era da globalização. Porto Alegre: UFRGS, 2008.

PLOEG, J. D. van der. Introducción. In: RAÚL, G.P.; RUBÉN, E. de D. Actores sociales y espacios protegidos. Tucumán: Magna Publicaciones, 2011.

RAY, C. Towards a meta-framework of endogenous development: repertoires, paths, democracy and rights. Sociologia Ruralis. Wageningen, v. 39, n. 4, p. 521-537, 1999.

RIO GRANDE DO SUL. Manual de conservação do solo e água. 3 ed. Porto Alegre, 1985.

RIO GRANDE DO SUL. Governo do Estado. Notícias. Emater apresenta diagnóstico do trabalho de 1.200 artesãos da Região Centro Sul. Porto Alegre, 2004. Disponível em: <http://www.rs.gov.br> . Acesso em: 27 junho 2015.

RIO GRANDE DO SUL. Assembléia Legislativa. Planejamento Estratégico do COREDE Centro SUl 2010-2020. Porto Alegre: Assembléia Legislativa, 2010. Disponível em: <http://www.al.rs.gov.br/forumdemocratico/> . Acesso em: 27 maio 2015.

RIO GRANDE DO SUL. Governo do Estado. Secretaria de Desenvolvimento Rural, Pesca e Cooperativismo. Programa Fortalecimento da Pecuária Familiar. Porto Alegre: SDR, $2012 \mathrm{a}$.

RIO GRANDE DO SUL. Governo do Estado. Termo de Cooperação Técnica 3729/2012. Secretaria de Desenvolvimento Rural, Pesca e Cooperativismo. Porto Alegre: SDR, $2012 \mathrm{~b}$. 
RIO GRANDE DO SUL. Governo do Estado. Unidades de Experimentação Participativa-UEPAs. Individuais e coletivas. Secretaria de Desenvolvimento Rural, Pesca e Cooperativismo. Porto Alegre: SDR, 2013.

RIO GRANDE DO SUL. Governo do Estado. Programa Aquisição de Reprodutores para Pecuária Familiar 2014. Secretaria de Desenvolvimento Rural, Pesca e Cooperativismo. Porto Alegre: SDR, $2014 a$.

RIO GRANDE DO SUL. Governo do Estado. Programa Melhoramento Genético. Edição 2014. Secretaria de Desenvolvimento Rural, Pesca e Cooperativismo. Porto Alegre: SDR, 2014b.

RIO GRANDE DO SUL. Governo do Estado.Atlas Socioeconômico Rio Grande do Sul. Conselhos Regionais de Desenvolvimento - COREDEs. Porto Alegre, 2015a. Disponível em: <http://www.seplan.rs.gov.br> . Acesso em: 28 maio 2015.

RIO GRANDE DO SUL. Secretaria Estadual de Agricultura e Pecuária. Programas. Porto Alegre, $2015 \mathrm{~b}$.

Disponível em: <http://www.agricultura.rs.gov.br> . Acesso em: 23 junho 2015.

ROEP, D.; WISKERKE, J.S.C. Reflecting on Novelty Production and Niche Management. In: WISKERKE, J.S.C.; PLOEG, J.D. van der. Seeds of Transitons. Assen: Royal Van Gorcum, p. 341-356, 2004.

SÃO JERÔNIMO. Prefeitura Municipal. Plano Ambiental Municipal. São Jerônimo: Coordenadoria Municipal de Meio Ambiente, 2009.

SILVA, Crstina Ennes da. Nas Profundezas da Terra: um estudo sobre a região carbonífera do Rio Grande do Sul (1883/1945). 2007.380 f. Tese 
(Doutorado em História) - Pontifícia Universidade Católica do Rio Grande do Sul, Porto Alegre, 2007.

SIMCH, A. Município de São Jerônimo. Monografia. Porto Alegre: Livraria Andradas, 1943.

SIMCH, A. Município de São Jerônimo. Monografia. Edição Especial Comemorativa. Porto Alegre: Câmara de Vereadores, 1961.

VENTURA, F.; MILONE, P. Novelty as Redefinition of Farm Boundaries. In: WISKERKE, J.S.C.; PLOEG, J.D. van der. Seeds of Transitions. Assen: Royal Van Gorcum, p. 57- 89, 2004. 
Mapeando a rede rural de desenvolvimento da pecuária familiar na Região Centro-

Sul...

Submetido em 02/03/2016

Aprovado em 26/07/2016

\section{Sobre os autores}

Marcelo Porto Nicola

Doutor em Desenvolvimento Rural pelo Programa de Pós-Graduação em Desenvolvimento Rural - PGDR da Universidade Federal do Rio Grande do Sul - UFRGS. Gerente Técnico da Estação Experimental Agronômica - EEA/FAGRO/UFRGS.

E-mail:mrprnicola@gmail.com

\section{Flávia Charão-Marques}

Doutora em Desenvolvimento Rural, Professora da Faculdade de Agronomia - FAGRO e do Programa de Pós-Graduação em Desenvolvimento Rural - PGDR da Universidade Federal do Rio Grande do Sul - UFRGS.

E-mail: flavia.marques@ufrgs.br 